Session 3232

\title{
Some Assessment Tools for Evaluating Curricular Innovations Outcomes
}

\section{Lueny Morell de Ramírez, José L. Zayas-Castro, Jorge I. Vélez-Arocho University of Puerto Rico-Mayagüez}

\begin{abstract}
One of the most critical aspects of the new ABET Engineering Criteria 2000 (EC-2000) is the existence of an outcomes assessment plan for program evaluation and continuous improvement. Outcomes assessment requires the generation of assessment tools or instruments to gather data that will document if a program's stated goals and objectives are being met and if students have acquired identified skills.

In 1994, a partnership of universities - called the Manufacturing Engineering Education Partnership (MEEP) - initiated the design and implementation of a novel undergraduate manufacturing program, better known as the Learning Factory ${ }^{1,2}$. This paper describes how MEEP designed the assessment strategy to evaluate the curricular innovation project outcomes, and presents some of the assessment instruments/tools designed. The tools developed, some in collaboration with industrial partners, were utilized for assessing overall and specific qualitative aspects of the program as well as student performance (e.g., teamwork skills and oral presentation/written skills). A total of 9 assessment instruments are presented. We believe that the Learning Factory as well as the project's assessment strategy and tools used comply with the new ABET Engineering Criteria 2000 (EC-2000).
\end{abstract}

\section{Introduction}

The creation and adoption of ABET's new accreditation standards is a historic move to promote innovation and continuous improvement in engineering education ${ }^{3}$. The core of EC 2000 is an outcomes assessment component that requires engineering programs to have in place a continuous process of evaluation and feedback, to ensure the improvement of the effectiveness of the program. There are numerous resources available for the development and implementation of outcomes assessment plans. For example, Rogers and Sando have prepared a user friendly, step by step booklet that presents eight steps in developing an assessment plan ${ }^{4}$. But regardless of how the assessment plan is developed, an effective plan must start with the identification of specific goals and objectives, definition of performance criteria, followed by the data collection

\footnotetext{
${ }^{1}$ Penn State University, University of Washington, and the University of Puerto Rico at Mayagüez in collaboration with Sandia National Laboratories. Project sponsored by the Technology Reinvestment Project. (TRP Project \#3018, NSF Award \#DMI9413880)

${ }^{2}$ John S. Lamancusa, Jens E. Jorgensen, and José L. Zayas, The Learning Factory - A New Approach to Integrating Design and Manufacturing into Engineering Curricula. ASEE Journal of Engineering Education, Vol 86, No.2, April 1997.

${ }^{3}$ George D. Paterson, Engineering Criteria 2000: A Bold New Change Agent, ASEE PRISM, September, 1997.

${ }^{4}$ Gloria M. Rogers and Jean K. Sando, Stepping Ahead: An Assessment Plan Development Guide, Foundation Coalition, 1996.
} 
methods and tools and, finally, the elaboration of feedback mechanisms. Data collection requires the development of assessment instruments focused for appropriate audiences.

Either prompted by EC-2000 or by the desire to improve quality standards, engineering programs have started to gather data for use in appraisal and improvements efforts in their institutional programs. For example, the College of Engineering of Auburn University has developed a plan to assess the quality of their instructional programs, designing various assessment tools for that purpose 5 . In the case of the Manufacturing Engineering Education Partnership (MEEP), a coalition of institutions who in response to industry needs, has developed an innovative manufacturing engineering curriculum and physical facilities for product realization (See Figure 1). This program offers a new paradigm for engineering education, providing a balance

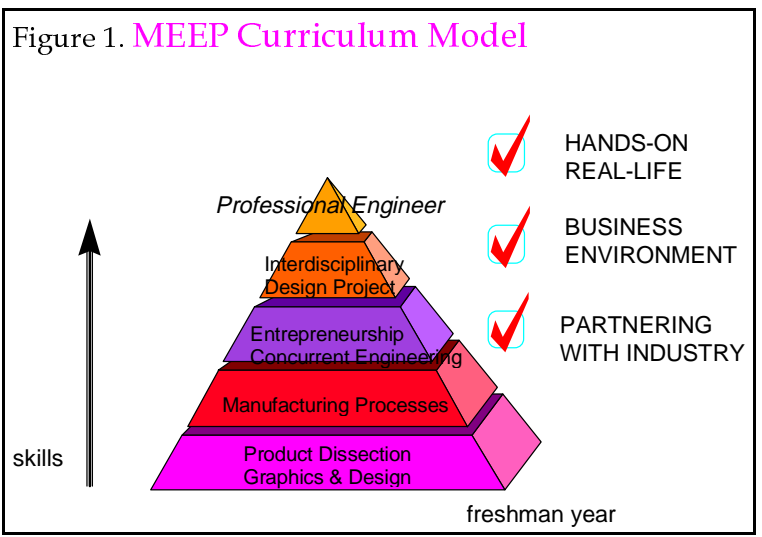
between theory and practice and emphasizing the development of basic skills in the student. The desired skills include communication, teamwork, business concerns and project management. Detailed information about the program can be found in the website, http://lfserver.lf.psu.edu/LF/col_home.html. A CD-ROM with curricular materials and publications can be requested. ${ }^{6}$

This paper describes 1) how MEEP designed the assessment strategy to evaluate this curricular innovation outcomes, and 2) some of the assessment instruments used. The tools developed, some in collaboration with industrial partners, were utilized to assess overall and specific qualitative aspects of the program, as well as student performance.

\section{Assessment Strategy}

Developing MEEP's assessment strategy proceeded rather easy because the project's goals and objectives had been clearly defined in the project's Strategic Plan. ${ }^{7}$ An assessment team was formed and the strategy discussed and shared with all the constituents (faculty, students, industrial partners). It was agreed that in order to have comprehensive and valid results the assessment plan should have the following elements:

- Internal (self-assessments)

- External (outside the partnership)

- Multiple criteria (variety of modes and viewpoints)

- Holistic (integrated)

- Qualitative and quantitative components.

\footnotetext{
${ }^{5}$ Larry D. Benefield, Landa L. Trentham, Karen Khodadadi, and Willieam F. Walker, Quality Improvement in a College of Engineering Instructional Program, Journal of Engineering Education, January, 1997.

${ }^{6}$ To request a CD-ROM contact John S. Lamancusa, Mechanical Engineering, Penn State University, email: js/3@psu.edu.

${ }^{7}$ Strategic Plan for the Manufacturing Engineering Education Partnership, September 1994. 
Because the granting agency (NSF) already had specified the quantitative data to be gathered, the assessment strategy focused on the qualitative aspects of the program. The assessment strategy developed for this purpose was as follows ${ }^{8}$ :

1. Outline of the project's goals, tasks, expected outcomes and metrics, as per the Strategic Plan.

2. Development of specific criteria and assessment tools.

3. Establishment of the assessment schedule.

4. Conduct assessments.

5. Report.

Once the project's goals were outlined, four matrices were developed (one for each of the project's tasks) which contained general and specific questions we thought the project's constituents wanted to be answered. Table 1 presents a sample from one of the matrices created. These matrices helped the assessment team develop the data collection approach and design the assessment instruments/ tools for the different audiences. Some of the tools used are presented in the next section.

Table 1. Sample from the Curriculum Development Matrix

Question 1: Was a new interdisciplinary, practice-based

curriculum, which emphasizes the interdependency of manufacturing and design, in a business environment developed?

\begin{tabular}{|c|c|c|c|}
\hline Subquestions & $\begin{array}{l}\text { Data } \\
\text { Collecti } \\
\text { on } \\
\text { Approac } \\
h\end{array}$ & $\begin{array}{l}\text { Respon } \\
\text {-dents : } \\
\text { student } \\
\text { s }(S), \\
\text { faculty } \\
(F) \\
\text { industr } \\
y(I)\end{array}$ & $\begin{array}{l}\text { Sched } \\
\text { ule }\end{array}$ \\
\hline $\begin{array}{l}\text { 1a. Did the program allow students to practice their engineering } \\
\text { science fundamentals in the solution of real problems? }\end{array}$ & $\begin{array}{l}\text { Question } \\
\text { n-aire } \\
\text { (Q) or } \\
\text { Focus } \\
\text { Group } \\
\text { (FG) } \\
\text { Samples }\end{array}$ & S, F, I & \\
\hline 1b. Are professional communication and team skills emphasized? & $\begin{array}{l}\text { Q or FG } \\
\text { Samples } \\
\text { Intervie } \\
\text { ws }\end{array}$ & $\mathrm{S}, \mathrm{F}, \mathrm{I}$ & \\
\hline $\begin{array}{l}\text { 1c. Are case studies, active learning techniques, and computer } \\
\text { technologies extensively used in the classroom? }\end{array}$ & $\begin{array}{l}\text { Q or FG } \\
\text { Samples }\end{array}$ & $\mathrm{S}, \mathrm{F}$ & \\
\hline
\end{tabular}

${ }^{8}$ Lueny Morell de Ramírez, Jose L. Zayas, John S. Lamancusa, and Jens Jorgensen, A Summative Assessment Strategy for a Multi-Institutuion, Multi-Task Project: the Case of MEEP, Proceedings of 1996 Frontiers in Education Conference, Slat-Lake City, Utah, November 1996.

Some Assessment Tools for Evaluating Curricular Innovations Outcomes 


\begin{tabular}{|c|c|c|c|}
\hline $\begin{array}{l}\text { 1d. Did the program provide previously unavailable opportunities } \\
\text { for hands on engineering experience in the Learning Factory? }\end{array}$ & $\mathrm{Q}$ or $\mathrm{FG}$ & $\mathrm{S}, \mathrm{F}$ & \\
\hline $\begin{array}{l}\text { 1e. Did the partner schools exchange information and learn from } \\
\text { each other's experiences? }\end{array}$ & $\mathrm{Q}$ or $\mathrm{FG}$ & $\mathrm{S}, \mathrm{F}, \mathrm{I}$ & \\
\hline $\begin{array}{l}\text { 1f. Did you take courses with students from disciplines other than } \\
\text { engineering? }\end{array}$ & $\mathrm{Q}$ or $\mathrm{FG}$ & $\mathrm{S}$ & \\
\hline $\begin{array}{l}\text { 1g. Did you develop or modify courses to accommodate multiple } \\
\text { engineering disciplines? }\end{array}$ & $\mathrm{Q}$ or $\mathrm{FG}$ & $\mathrm{F}$ & \\
\hline \multicolumn{4}{|l|}{$\begin{array}{l}\text { Question 2: Was a new paradigm for coalition-wide courses } \\
\text { development, sharing and export to the academic } \\
\text { community at-large developed? }\end{array}$} \\
\hline Subquestions & $\begin{array}{l}\text { Data } \\
\text { Collecti } \\
\text { on } \\
\text { Approac } \\
h \\
\end{array}$ & $\begin{array}{l}\text { Respon } \\
\text { dents }\end{array}$ & $\begin{array}{l}\text { Sched } \\
\text { ule }\end{array}$ \\
\hline $\begin{array}{l}\text { 2a. Were resources and ideas shared, avoiding redundant efforts? } \\
\text { Were new technologies for communication utilized, achieving } \\
\text { consensus on curriculum content? }\end{array}$ & $\begin{array}{l}\text { Q or FG } \\
\text { Samples }\end{array}$ & $\mathrm{S}, \mathrm{F}, \mathrm{I}$ & \\
\hline $\begin{array}{l}\text { 2b. Were jointly developed curriculum materials easily transported } \\
\text { among the MEEP partners, and exported to the academic } \\
\text { community at large? }\end{array}$ & Q or FG & $\mathrm{S}, \mathrm{F}$ & \\
\hline $\begin{array}{l}\text { 2c. Were computer technologies, multimedia and electronic } \\
\text { communications used? }\end{array}$ & $\begin{array}{l}\text { Q or FG } \\
\text { Samples }\end{array}$ & $\mathrm{S}, \mathrm{F}$ & \\
\hline $\begin{array}{l}\text { 2d. Did you participate with partnership professors to develop } \\
\text { course materials? How effective was the collaboration? }\end{array}$ & $\mathrm{Q}$ or $\mathrm{FG}$ & $\mathrm{F}$ & \\
\hline
\end{tabular}

\section{Assessment Instruments/Tools}

In this section, several of the assessment instruments/tools utilized are presented. They are presented in three categories: Project/Program Assessment Tools, Student Performance Assessment Tools, and, Course and Curricular Materials Assessment Tools. Some of the instruments were used coalition-wide and others were used at one or more of the partnership universities. Some of the tools (e.g., surveys, focus group questions) were developed with the help of our industrial partners. Assessment results have been published elsewhere. ${ }^{9}$

\section{Project/Program Assessment Tools ${ }^{10}$}

- Surveys: Four surveys were developed from the assessment matrices, focused on different audiences: students, faculty, industry and other institutions. Issues and items in the surveys reflected some of the ways in which the Manufacturing Engineering Partnership (MEEP) could be described. Respondents were asked to fill in the degree to which they agreed of the experiences they were exposed to which were provided by

\footnotetext{
${ }^{9}$ Lueny Morell de Ramírez, José L. Zayas, John Lamancusa, Jens Jorgensen, The Manufacturing Engineering Education Partnership: Program Outcomes Assessment Results, Frontiers in Education Conference Proceedings, Pittsburgh, November, 1997.

${ }^{10}$ Assessment instruments are included in the Appendix. 
the program. Each survey provided specific questions depending on the audience surveyed. Questions ranged from individual perceptions of the quality of specific courses and activities, to faculty evaluations, relationship with industry, to more general questions surveying the overall impact. The surveys provided also for comments and suggestions for improvement. Industry and student surveys can be reviewed in the Appendix.

- Industry/Faculty Focus Group: Faculty and industrial partners from the three institutions discussed their experiences and their perceptions as to what made the partnership a success. A discussion group was created on-line, and opinions shared and gathered for a period of two months.

- External Assessors: A group of experts - who either had experience in manufacturing engineering, or were familiar with our work or with similar partnerships/ learning goals - evaluated the project's deliverables. They participated in partnership meetings, talked to industry partners, students and faculty, visited facilities, completed the survey, or browsed course materials in national conferences and meetings.

Student Performance Assessment Tools

- Teamwork skills assessment instrument: In order to assess the students' performance in working in teams, an assessment instrument or form was developed. The form asked students to to explain their decision-making process during a specific task they had to achieve (for example, design phase) and their strategies to solve conflicts in design teams. Besides assessing student performance for grading purposes, this tool helped faculty to detect if students needed more training on how to work in teams. Answers provided by the students were discussed in class.

- Peers Evaluation Form: At the end of the semester, students evaluate peers in their teams. They assess each team member in terms of the effort (0-3) and the grade they assess the work (in percent).

- Oral/written communication assessment instruments/tools: Two assessment tools were used to evaluate the students' oral and written communications skills. These forms were used by faculty as well as peers in evaluating student oral presentations and written reports. Feedback from peers was provided to the student teams at the conclusion of the presentation.

Course and Curricular Materials Assessment Tools

- Course Evaluation and Assessment of Skills and Knowledge Instrument: In order to evaluate the mastery and level of knowledge and skills developed by the students in MEEP courses and to establish the effectiveness of lectures and experiences, as well as course logistics, an assessment instrument was designed. This generic template is adapted by the faculty member, customizing it to the individual course. 
- Lecturer Evaluation Form: Some of the MEEP courses offered at UPRM are team taught. A lecturer evaluation instrument was designed to determine each individual lecture's effectiveness.

- CD-ROM Curricular Materials Assessment Tool: One of the products of the program is a CD-ROM with all the curricular/course materials developed. An assessment form was included in the CD-ROM to evaluate the contents as well as the quality of the materials in the CD-ROM.

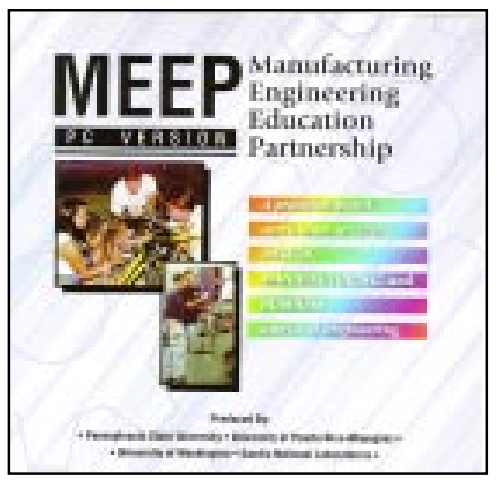

\section{Conclusion and Outcomes of Assessment}

Developing assessment instruments is an important element in evaluating new as well as existing education innovation projects. The Manufacturing Engineering Education Partnership (MEEP) was successful not only in achieving its goals and objectives, but also, in gathering and documenting the quantitative and qualitative data to support its success. Developing a sound outcomes assessment plan requires the existence of clear-stated goals, such as included in a strategic plan, together with appropriate instruments and tools. The assessment strategy and the assessment tools herein described can be used and adapted for program accreditation and outcomes assessment purposes, such as the new EC-2000 requirements. Due to the success of our project and the evidence gathered from the project's outcomes assessment reports, one of our industrial partners, Robert T. George (Dupont Corporation), an Industry Fellow at Penn State, won an NSF GOALI award and is currently benchmarking industry/academic partnerships in engineering education. A report is due soon.

\section{BIOGRAPHICAL INFORMATION}

\section{LUENY MORELL DE RAMÍREZ}

Professor of Chemical Engineering and Director of the Curriculum Innovation Center of the Puerto Rico Alliance for Minority Participation Project, University of Puerto Rico at MayagüezAddress: P.O. Box 9040 College Station, Mayagüez, P.R. 00681-5000. Voice: 787-265-3826; Fax: 787-832-0119; e-mail: 1ueny@exodo.upr.clu.edu

\section{JOSÉ L. ZAYAS-CASTRO}

Professor of Industrial Engineering and Associate Dean of Engineering, University of Puerto Rico at Mayagüez. Address: P.O. Box 9040 College Station, Mayagüez, P.R. 00681-5000. Voice: (787) 832-4040 ext. 3823; Fax: (787) 833-6965;

e-mail: jzayas@exodo.upr.clu.edu

\section{JORGE I. VÉLEZ-AROCHO}

Professor of Business Administration and Co-Director of CoHemis Center, University of Puerto Rico at Mayagüez. Address: P.O. Box 5000 College Station, Mayagüez, P.R. 00681-5000. Voice: 787-265-3805, Fax: 787-265-6340, email: jvelez@exodo.upr.clu.edu 


\section{APPENDIX}

List of Assessment Instruments Included:

1. Industry Survey

2. Student Survey

3. Teamwork Experiences Assessment Form

4. Written Report Assessment

5. Oral Presentation Assessment

6. Peers Evaluation Form

7. Lecturer Evaluation Form

8. Course Evaluation and Assessment of Skills and Knowledge

9. CD-ROM Course Material Assessment Form 


\section{Manufacturing Engineering Education Partnership \\ MEEP \\ INDUSTRY SURVEY}

The Learning Factory is a new practice based curriculum and physical facilities for product realization that has been developed at three institutions: Penn State, the University of Washington, the University of Puerto Rico at Mayagüez in collaboration with Sandia National Labs. Its goal is to provide an improved educational experience that emphasizes the interdependency of manufacturing and design in a business environment. The key element in this approach is active learning - the combination of curriculum revitalization with coordinated opportunities for application and hands on experience.

This questionnaire has been designed to assess the performance and products of this program. Please answer it to the best of your knowledge.

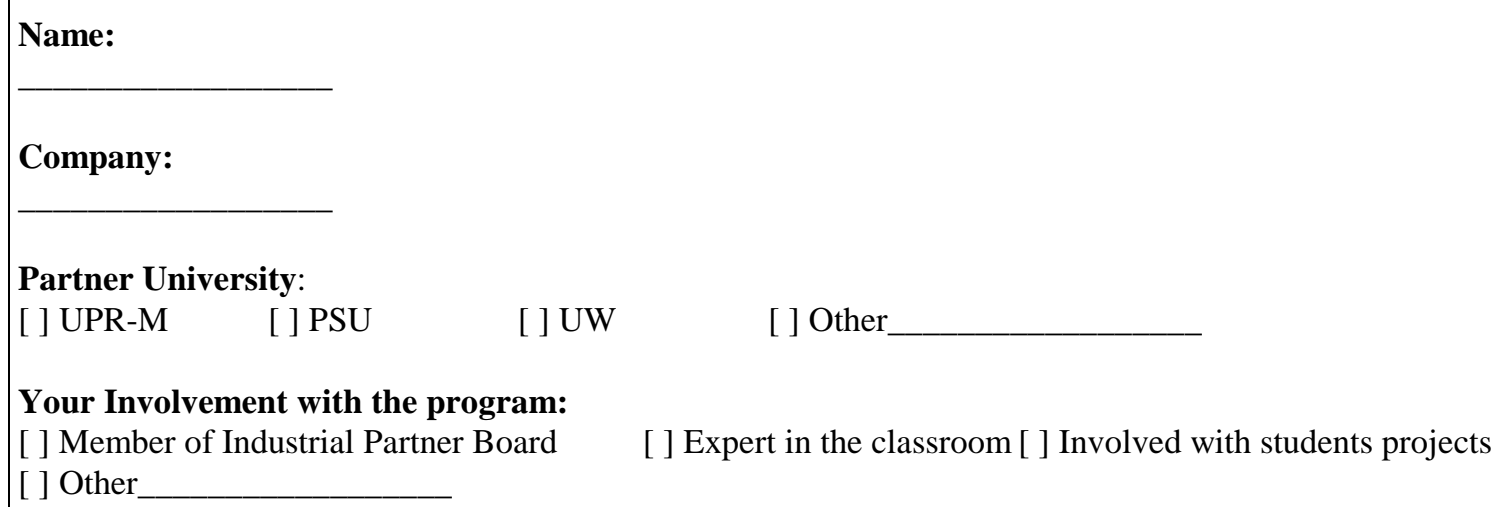

\section{Instructions:}

The following items reflect some of the ways in which the Manufacturing Engineering Partnership (MEEP) can be described. Please fill in the numbered circle which indicates THE DEGREE TO WHICH YOU AGREE that each item is descriptive of the experiences you were exposed to and provided by the program. If you have no information or feel an item does not apply, please fill in the N/A circle.

The program allowed students to practice engineering science fundamentals in the solution of real problems.
[ ] Strongly Agree
[] Agree
[ ] Neutral
[ ] Disagree
[ ] Strongly Disagree
[ ] N/A

Professional communications skills were enhanced.

$\begin{array}{lllll}\text { [ ] Strongly Agree [ ] Agree [ ] Neutral [ Disagree } & \text { [ ] Strongly Disagree [ ] N/A }\end{array}$

Team work skills were enhanced.

[ ] Strongly Agree [ ] Agree [ ] Neutral [ ] Disagree [ ] Strongly Disagree [ ] N/A

The partner schools learned from each other's experience.

[ ] Strongly Agree [] Agree [ ] Neutral [ ] Disagree [ ] Strongly Disagree [ ] N/A

Resources and ideas were shared, avoiding redundant efforts.

[ ] Strongly Agree [] Agree [ ] Neutral [ ] Disagree [ ] Strongly Disagree [ ] N/A

Real life problems were provided.

[ ] Strongly Agree [ ] Agree [ ] Neutral [ ] Disagree [ ] Strongly Disagree [ ] N/A

New technologies for communication were utilized on curriculum content.

[ ] Strongly Agree [ ] Agree [ ] Neutral [ ] Disagree $\quad$ [ ] Strongly Disagree [ ] N/A

Some Assessment Tools for Evaluating Curricular Innovations Outcomes $\quad 8$ ASEE Conference

June 1998 
The local Industrial Advisory Board (IAB) provided quality strategic and operation guidance to the local institution. [ ] Strongly Agree [] Agree [ ] Neutral [ ] Disagree [ ] Strongly Disagree [ ] N/A

The local IAB supported MEEP's activities providing financial and/or non financial resources.

[ ] Strongly Agree [] Agree [ ] Neutral [ ] Disagree [ ] Strongly Disagree [ ] N/A

There was good communication between industrial sponsors and the institution.

[] Strongly Agree [ ] Agree [ ] Neutral [ ] Disagree [ ] Strongly Disagree [ ] N/A

Each institution provided the IAB the right information in a timely fashion.

[] Strongly Agree [] Agree [] Neutral [ ] Disagree [ ] Strongly Disagree [ ] N/A

The MEEP's Industrial Advisory Board (IAB) evaluated the overall progress of the program.

[ ] Strongly Agree [] Agree [ ] Neutral [ ] Disagree [ ] Strongly Disagree [ ] N/A

The partnership reported progress and activities related to participation in curriculum development.

[ ] Strongly Agree [ ] Agree [ ] Neutral [ ] Disagree [ ] Strongly Disagree [ ] N/A

The MEEP's IAB provided support in actions/activities that are relevant to the program.

[ ] Strongly Agree [] Agree [ ] Neutral [ ] Disagree [ ] Strongly Disagree [ ] N/A

The partnership reported progress and activities related to participation in the classroom teaching.

[ ] Strongly Agree [ ] Agree [ ] Neutral [ ] Disagree [ ] Strongly Disagree [ ] N/A

Students completing the MEEP program are more useful to our industry.

[ ] Strongly Agree [ ] Agree [ ] Neutral [ ] Disagree [ ] Strongly Disagree [ ] N/A

My Industry and company is more likely to hire a MEEP trained student than a traditionally trained student.

[] Strongly Agree [] Agree [ ] Neutral [ ] Disagree [ ] Strongly Disagree [ ] N/A

Would you encourage other companies to participate in the program and coalition? Why?

What can be improved with MEEP?

Comments: 


\section{Manufacturing Engineering Education Partnership \\ MEEP \\ STUDENT SURVEY}

The Learning Factory is a new practice based curriculum and physical facilities for product realization. Its goal is to provide an improved educational experience that emphasizes the interdependency of Manufacturing and design in a business environment. The key element in this approach is active learning - the combination of curriculum revitalization with coordinated opportunities for application and hands on experience.

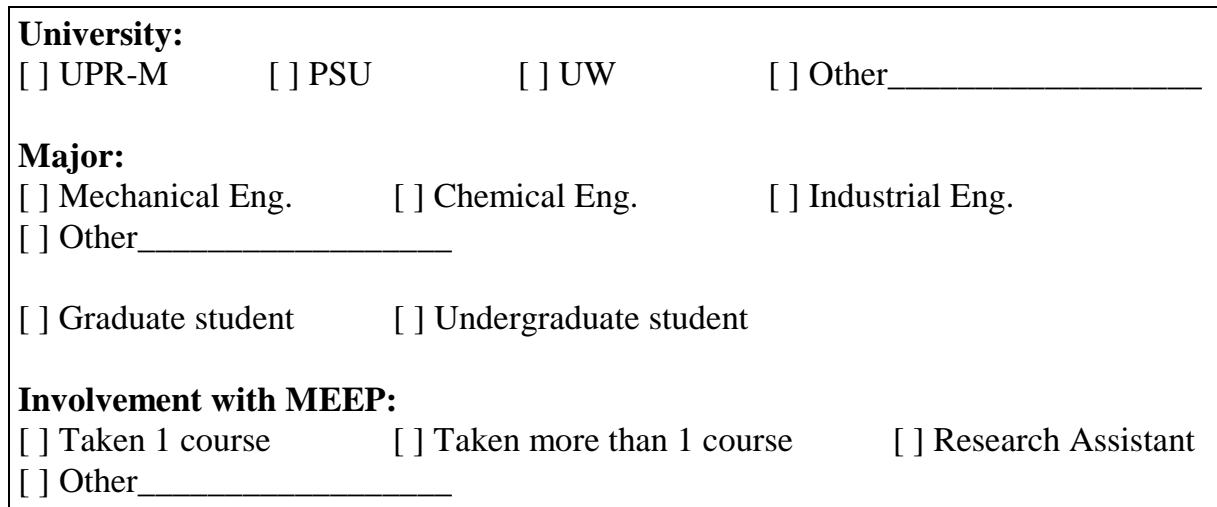

The program courses at your institution were offered as: (Check all that apply)

[ ] as part of a minor [ ] as electives [ ] as part of a degree option [ ] required for the major

[ ] Other

The courses were:

[ ] interdisciplinary [ ] engineering students only [ ] students from only one department

\section{Instructions:}

The following items reflect some of the ways in which the Manufacturing Engineering Partnership (MEEP) can be described. Please fill in the checkbox which indicates THE DEGREE TO WHICH YOU AGREE that each item is descriptive of the experiences you were exposed to and provided by the program. If you have no information or feel an item does not apply, please fill in the N/A checkbox.

The program allowed you to practice engineering science fundamentals in the solution of real problems.
[ ] Strongly Agree
[ ] Agree
[ ] Neutral
[ ] Disagree
[ ] Strongly Disagree
[ ] N/A

Professional communications skills were emphasized.

[ ] Strongly Agree [] Agree [ ] Neutral [ ] Disagree [ ] Strongly Disagree [ ] N/A

Team work skills were emphasized.

[ ] Strongly Agree [ ] Agree [ ] Neutral [ ] Disagree [ ] Strongly Disagree [ ] N/A

Case studies were extensively used in the courses.
[ ] Strongly Agree
[ ] Agree
[ ] Neutral
[ ] Disagree
[ ] Strongly Disagree
[ ] N/A

Active learning activities were extensively used in the courses.

\begin{tabular}{|c|c|c|c|c|c|}
\hline [ ] Strongly Agree & [ ] Agree & [ ] Neutral & [ ] Disagree & [ ] Strongly Disagree & [ ] N/A \\
\hline \multicolumn{6}{|c|}{ Computer technologies were extensively used in the classroom. } \\
\hline [ ] Strongly Agree & [ ] Agree & [ ] Neutral & [ ] Disagree & [] Strongly Disagree & [ ] N/A \\
\hline
\end{tabular}

Some Assessment Tools for Evaluating Curricular Innovations Outcomes 
The courses were set in an industrial like setting.

[ ] Strongly Agree [ ] Agree [ ] Neutral [ ] Disagree [ ] Strongly Disagree [ ] N/A

The MEEP courses you took had more design/manufacturing content than other similar courses at your institution.
[ ] Strongly Agree
[ ] Agree
[ ] Neutral
[ ] Disagree
[ ] Strongly Disagree
[ ] N/A

The Learning Factory (LF) provided you with a fully integrated activity center for the creation and implementation of products and processes.

[ ] Strongly Agree [ ] Agree [ ] Neutral [ ] Disagree [ ] Strongly Disagree [ ] N/A

The LF facility was well equipped to give me real life experience in "state of the art" processes.

[ ] Strongly Agree [] Agree [] Neutral [ ] Disagree [ ] Strongly Disagree [ ] N/A

The LF facility was professionally staffed to allow me to experiences the product/process realizations.

[ ] Strongly Agree [ ] Agree [ ] Neutral [ ] Disagree [ ] Strongly Disagree [ ] N/A

I feel that my participation in the MEEP Program has improved my career opportunities.

[] Strongly Agree [] Agree [ ] Neutral [ ] Disagree [ ] Strongly Disagree [ ] N/A

I learn better from classroom lecture then hands-on laboratory experience.

[ ] Strongly Agree [] Agree [] Neutral [ ] Disagree [ ] Strongly Disagree [ ] N/A

The MEEP courses provided more to my professional development than typical courses.

[ ] Strongly Agree [] Agree [ ] Neutral [ ] Disagree [ ] Strongly Disagree [ ] N/A

My MEEP course(s) were more fun than my typical engineering courses.

[] Strongly Agree [] Agree [ ] Neutral [ ] Disagree [ ] Strongly Disagree [ ] N/A

Because of the MEEP courses, I have a much better understanding of what engineering is.

[] Strongly Agree [] Agree [ ] Neutral [ ] Disagree [ ] Strongly Disagree [ ] N/A

As a result of this course, I am more confident in my ability to solve real-life problems.

[ ] Strongly Agree [] Agree [ ] Neutral [ ] Disagree [ ] Strongly Disagree [ ] N/A

As a result of this course, I feel more confident in my abilities to process information, and teach myself new things, without the aid of an instructor.

[ ] Strongly Agree [] Agree [ ] Neutral [ ] Disagree [ ] Strongly Disagree [ ] N/A

The MEEP instructors were superior to my typical university instructors.

[ ] Strongly Agree [ ] Agree [ ] Neutral [ ] Disagree [ ] Strongly Disagree [ ] N/A

COMMENTS: 


\section{University of Puerto Rico \\ Mayagüez Campus \\ ADMI 3100 - TECHNOLOGY BASED ENTREPRENEURSHIP \\ TEAMWORK EXPERIENCES ASSESSMENT FORM}

Please answer the following questions regarding your work as a team for the completion of the required task.

\section{TASK(S): PRODUCT DESIGN, DECISION-MAKING}

1. In chronological order, list what your team did during the design phase. Explain how tasks were distributed, how decisions were made.

2. What facilitated the decision-making process?

3. What was your contribution to the team when decisions had to be taken?

4. What do you think you would like to do differently the next time when working in a team?

NAME

TEAM

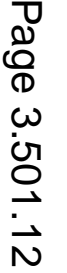


University of Puerto Rico

Mayagüez Campus

ADMI 3100 - TECHNOLOGY BASED ENTREPRENEURSHIP

WRITTEN REPORT ASSESSMENT

Name

Team date

Evaluator

Report Title

\begin{tabular}{||l|l||}
\hline \multicolumn{1}{|c|}{ CATEGORY } & ASSESSMENT \\
\hline Cover, title page, table of contents, list of figures, etc. & $/ 10$ \\
\hline Abstract & $/ 15$ \\
\hline Introduction* & $/ 10$ \\
\hline Body* & $/ 20$ \\
\hline Conclusions/recommendations* & $/ 15$ \\
\hline Language/grammar/clarity & $/ 05$ \\
\hline Figures/tables & $/ 05$ \\
\hline Bibliography/references & $/ 05$ \\
\hline GENERAL & $/ 15$ \\
\hline \multicolumn{1}{|c|}{ TOTAL } & $/ \mathbf{1 0 0}$ \\
\hline
\end{tabular}

* Considerations for the FINAL REPORT ONLY:

- Market definition/product need

- Goals \& objectives of design

- Work/action Plan

- Knowledge \& application of concepts

- Engineering method

- Other

\section{COMMENTS:}


University of Puerto Rico

Mayagüez Campus

ADMI 3100 - TECHNOLOGY BASED ENTREPRENEURSHIP

ORAL PRESENTATION ASSESSMENT

Name of the Company:

Team Date Evaluator

Part 1 - PRESENTATION

\begin{tabular}{|l|c|c|c|c|c|c|}
\hline CATEGORY & $\mathbf{0}$ & $\mathbf{1}$ & $\mathbf{2}$ & $\mathbf{3}$ & $\mathbf{4}$ & $\mathbf{5}$ \\
\hline Organization & & & & & & \\
\hline Level & & & & & & \\
\hline Knowledge of Material & & & & & & \\
\hline Time & & & & & & \\
\hline Delivery/Transmission of Material & & & & & & \\
\hline Quality of Language & & & & & & \\
\hline Order & & & & & & \\
\hline Management of Questions & & & & & & \\
\hline Ability to Discuss Project and Methodology & & & & & & \\
\hline Personal Appearance/Manners & & & & & & \\
\hline TOTAL & & & & & & \\
\hline
\end{tabular}

PART 2 - CONTENTS

\begin{tabular}{|l|c|c|c|c|c|c|}
\hline CATEGORY & 0 & $\mathbf{1}$ & $\mathbf{2}$ & $\mathbf{3}$ & $\mathbf{4}$ & $\mathbf{5}$ \\
\hline Introduction/Background & & & & & & \\
\hline Body & & & & & & \\
\hline Conclusion & & & & & & \\
\hline TOTAL & & & & & & \\
\hline
\end{tabular}

Part 3-Overall

\begin{tabular}{|l|c|c|c|c|c|c|}
\hline CATEGORY & 0 & $\mathbf{1}$ & $\mathbf{2}$ & $\mathbf{3}$ & $\mathbf{4}$ & $\mathbf{5}$ \\
\hline Overall Quality of the Presentation & & & & & & \\
\hline Perception of Potential Success in a Competitive Forum & & & & & & \\
\hline Perception of Potential in Achieving Results & & & & & & \\
\hline TOTAL & & & & & & \\
\hline
\end{tabular}

GRAND TOTAL

COMMENTS: 
University of Puerto Rico

Mayagüez Campus

ADMI 3100 - TECHNOLOGY BASED ENTREPRENEURSHIP

PEER EVALUATION FORM

Name of the Company:

Team

Date

Evaluator (VOLUNTARY)

Please describe the effort of your peers so far.

Use the following code for evaluation:

3 Excellent job

1 We had to force him/her to work
2 Did his/her share

0 Did not work at all

Write the name of your team members in the table below and evaluate them.

\begin{tabular}{|l|c|c|}
\hline Student Name & $\begin{array}{c}\text { Evaluation } \\
\text { (From 0 to 3) }\end{array}$ & $\begin{array}{c}\text { Evaluation } \\
\text { (From 0 to 100\%) }\end{array}$ \\
\hline & & \\
\hline & & \\
\hline & & \\
\hline & & \\
\hline
\end{tabular}

Comments: 
University of Puerto Rico

Mayagüez Campus

ADMI 3100 - TECHNOLOGY BASED ENTREPRENEURSHIP

PROFESSOR/LECTURER EVALUATION FORM

Lecture Title:

Speaker:

Date:

Please evaluate the organization, contents and effectiveness of the lecture, using the following scale: $\mathbf{1}=\mathbf{l o w}, \mathbf{5}=$ high.

\begin{tabular}{|l|l|l|l|l|l|}
\hline CATEGORY/ITEM & LOW 1 & $\mathbf{2}$ & $\mathbf{3}$ & $\mathbf{4}$ & HIGH 5 \\
\hline Organization & & & & & \\
\hline Overall Quality & & & & & \\
\hline Clarity in Exposure & & & & & \\
\hline Comprehension of Material Presented & & & & & \\
\hline Adequacy of Materials, Illustrations, Examples & & & & & \\
\hline Teaching Methodology & & & & & \\
\hline Knowledge of Subject & & & & & \\
\hline Ability to Transmit Knowledge & & & & & \\
\hline Explanations and Illustrations & & & & & \\
\hline My ability to use this New Information & & & & & \\
\hline My Overall Understanding of the Subject & & & & & \\
\hline
\end{tabular}

Evaluator (voluntary):

Please answer briefly the following questions and please feel free to add any comments on the back.

1. What did you like about the lecture?

2. What did you dislike?

3. Suggestions to improve the lecture?

MANUFACTURING ENGINEERING EDUCATION PARTNERSHIP

MEEP

University of Puerto Rico

Mayagüez Campus

COURSE EVALUATION

And

ASSESSMENT OF SKILLS and KNOWLEDGE

Some Assessment Tools for Evaluating Curricular Innovations Outcomes 
Course:

Instructor:

The purpose of this assessment is:

- to determine your perception of mastery/level of knowledge and skills developed by the students in this course, and

- to establish the effectiveness of lectures and experiences, as well as of the logistics used.

The results of this assessment will help the instructor in charge of the course to better plan and adjust the course's agenda in the future.

\section{PART I: GENERAL OBJECTIVES AND SKILLS}

Directions:

Using the scale below, please evaluate (*) your perception of the mastery of skills and experience the students developed in this course in the areas specified.

\section{N: no skills/no experience \\ R: rudimentary skills/very little experience \\ F: functionally adequate skills/some experience \\ A: advance skill/extensive experience}

\begin{tabular}{||l|l||}
\hline \hline \multicolumn{1}{||c||}{ area } & $*$ \\
\hline skill 1 & \\
\hline skill 2 & \\
\hline & \\
\hline objective 1 & \\
\hline objective 2 & \\
\hline
\end{tabular}


PART II: CONTENT, LECTURES AND EXPERIENCES

Directions:

In this part, please indicate $(*)$ your perception of the lectures and activities' effectiveness, using the following scale: 0: not effective; would eliminate

1: moderately effective; significant changes (specify)

2: effective; minor changes (specify)

3: very effective; would not change

\begin{tabular}{||l|l|l||}
\hline \multicolumn{1}{|c|}{ module/lectures } & $*$ & comments \\
\hline Module 1: TITLE & & \\
\hline Module 2: TITLE & & \\
\hline & & \\
\hline & & \\
\hline Module n: TITLE & & \\
\hline
\end{tabular}

\section{PART III: COURSE LOGISTICS}

Directions:

Please indicate (*) how you feel regarding the various aspects designed for the course, using the following scale:

0: inadequate; disliked, needs re-engineering!

1: somewhat adequate; needs enhancement

2: adequate; minor changes

3: adequate; no change

\begin{tabular}{||l|l|l||}
\hline \multicolumn{1}{|c|}{ area } & $*$ & \multicolumn{1}{c||}{ comments } \\
\hline Number of meetings & & \\
\hline Kinds of assessment techniques & & \\
\hline Requirements & & \\
\hline Number of lectures & & \\
\hline Number of plant trips & & \\
\hline Topics covered & & \\
\hline Course coordination & & \\
\hline Other: & & \\
\hline
\end{tabular}


Would you recommend this course to other students? Explain.

Do you think your expectations were met?

YES/NO. Explain.

Suggestions:

Your overall rating of the course:

110. 


\section{The Manufacturing Engineering Education Partnership (MEEP)}

CD-ROM Assessment Form

Please review this CD-ROM and, to the best of your knowledge, answer the questions that follow regarding the contents and quality of the curricular materials included. We would also like to know how useful these materials could be to you or to any institution willing to adopt or adapt them. Your feedback will help the Partnership in its effort to fine tune the curricular products developed.

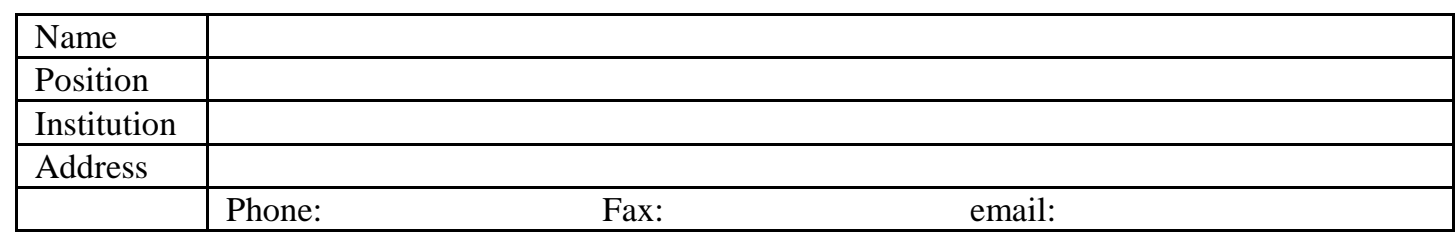

The MEEP CD-ROM contains the following items:

\section{Background Information}

- Information about MEEP

- Video

- MEEP Publications

\section{Course Materials}

- Product Dissection Course

- Technology-based Entrepreneurship Course

- Concurrent Engineering Modules

- Process Quality Engineering Course

- Rapid Prototyping Technology Module

\section{Regarding Background Information:}

- Did you understand the program, as described in the Information about MEEP section?

- Was the video about the program useful in understanding the goals and objectives of the Partnership?

- Did the publications about MEEP provide more details about the different aspects of the program (e.g. goals, approach, products, assessment)?

- $\quad$ Regarding the Course Materials: How would you rate the content and quality of the course materials? Use the following rating: 1 (poor); 5 (excellent)

\begin{tabular}{|l|l|l|l|}
\hline & Content & Quality & Comments \\
\hline Product Dissection Course & & & \\
\hline Entrepreneurship Course & & & \\
\hline Concurrent Engineering Modules & & & \\
\hline Process Quality Engineering Course & & & \\
\hline $\begin{array}{l}\text { Rapid Prototyping Technology } \\
\text { Module }\end{array}$ & & & \\
\hline
\end{tabular}


III. Regarding the use of the contents of the CD-ROM

- Will you use the curricular materials included? If the answer is yes, how would you use them?

- Would you like to learn more about MEEP, learn how to use these materials with the course developers, and how to develop a Learning Factory in you institution?

File:papers/ASEE98-AssessTools.doc 